\title{
EDITORIAL
}

\section{A research agenda for alternative forms of corporate governance in Journal of Management \& Organization}

\section{INTRODUCTION}

The aftermath of the global financial crisis has led to a robust public debate on corporate governance practice in the modern business firm, especially large stock exchange listed financial institutions (O'Shannassy, 2015a). We argue here that this public debate has influenced the academic debate on corporate governance across the range of large, medium-size and small enterprises only to a limited extent at the moment. This is despite the fact there is widespread agreement that researching alternative governance forms (e.g., small family-owned firms) can inform extant theory and have positive practical implications as well. There is also now a growing realization that the dominant research focus on the governance of large, stock exchange listed companies is taking attention away from the fact that these large companies are in decline in actual number (Davis, 2016). This is the case in legal jurisdictions such as the United States and Germany as other lower cost and nimble (e.g., online retailers, pop-up businesses) economic forms of organization emerge (Davis, 2016). Therefore there is need for a greater balance in the academic and executive management literature regarding the types of companies and the size of companies that are the subject of research (O'Shannassy, 2015a). It is not surprising then, that the Academy of Management also highlighted this issue, among others by choosing the theme of Opening Governance as the theme of the Academy of Management Conference 2015 in Vancouver.

Despite these calls for study of alternative corporate governance models, at first sight little progress appears to have been made. Even though there is a continuous stream of papers dealing with these issues, the quantity of papers on alternative corporate governance models is small in comparison with papers focusing on traditional governance structures. Conceptual frameworks for analyzing alternative governance models also have not reached a comparable state of maturity. Contributions in this area are only in their infancy but seem promising. For example, work by Grandori (2016) and Puranam, Alexy, and Reitzig (2014) provide useful analytical lenses. From an empirical perspective a positive sign is that in Journal of Management \& Organization (JMO) a stream of papers has emerged over recent years which have started to tackle these issues as well. Given this background in this introduction to the themed issue here we would like to make this stream more explicit and point towards a research agenda contributors to JMO could pursue more consistently. Various papers in JMO have presented relevant insights. By making a contribution here in this Editorial at creating an overarching research strategy out of these individual contributions, we hope to spark a debate that will increase research attention on alternative corporate governance forms.

To achieve this outcome we compare 'traditional governance' with 'alternative governance' as it seems to be emerging in JMO. For the sake of brevity, we would like to summarize the dominant view of traditional governance to a few stylized facts. Inevitably, this does not do justice to the variety of research that has been done in this area. However, it serves our purpose here, which is to point to an emerging alternative governance paradigm that is specifically relevant to the ANZAM community. In this approach of stylized facts, the dominant view on corporate governance focuses on three elements. First, the influence of the chief executive officers (CEO) with an emphasis on their transactional behavior; second public companies listed on the stock exchange; and third shareholder value (Kiel \& Nicholson, 2003; Taniman \& O’Shannassy, 2015). The theoretical tools used to study this dominant paradigm are usually taken from economics and specifically from agency and transaction cost theory. 
The strength of this stream of research is that it has been able to uncover a clear logic between these three elements: shareholders in publicly owned firms aim to optimize their value (profits, dividends and/or share price). To achieve that end they appoint a knowledgeable full-time manager overseen by non-executive directors on the company board. To incentivize the manager to create shareholder value and avoid opportunistic behavior, the manager receives shares and/or share options in the company and is empowered to enter into all kinds of transactions internally and externally to maximize shareholder value. Theoretical debates in this research stream center around questions such as whether it is mainly agency or transaction costs that determine the governance approach including 'day-to-day' management choices of the firm, which mechanisms are used to curb manager as agent self-interest and opportunism in organizations, and under which circumstances firms enter into mergers, acquisitions and alliances (Williamson, 1975; Jensen \& Meckling, 1976). This model received extensive criticism, among others in a vigorous debate between Ghoshal, Moran and Williamson (Ghoshal \& Moran, 1996; Moran \& Ghoshal, 1996; Williamson, 1996). Nevertheless, the model was very successful academically and delivered a plethora of insights.

It is not our argument that this theoretical model should be abandoned. Instead we argue that there should be more attention in academia to study alternatives, especially because these models assume the presence of a group of anonymous shareholders. Looking through the past years of JMO, we find some of the building blocks for an alternative for the CEO/public ownership/shareholder value tripod of traditional governance. Putting these building blocks together we define that alternative as top management teams (TMT)/family-owned firms/shared value (i.e., shareholders and stakeholders together). JMO has published certain papers (e.g., Pichlak, 2016) that look at TMTs where more organic leadership styles have been exhibited. This is in contrast to the traditional focus on the CEO as an individual with a transactional leadership style (although papers about that approach are certainly not absent from JMO!). There is also widespread interest in family-owned firms as an alternative to those listed on the stock exchange (e.g., Liu, Valenti, \& Chen, 2016). Finally, we observe that JMO does give much attention to corporate social responsibility, corporate philanthropy and stakeholder value. Following these recent insights we interpret this trend as an increase of interest in shared value (Porter \& Kramer, 2011). There are several papers that have addressed either one or two of these elements (e.g., Tian, Liu, \& Fan, 2015). We propose it may be interesting to look at these three elements in conjunction and to work towards finding some logic between these three elements that is as powerful as the logic of the traditional governance perspective.

Some JMO papers already make important steps by combining two of the elements of the alternative governance model. For example papers report research on TMT in family firms (Cabrera-Suárez \& Martín-Santana, 2013), family representatives in TMT (Sanchez-Famoso, Maseda, \& Iturralde, 2017), the role of boards in family firms (Basco \& Voordeckers, 2015), family firms and philanthropy (Du, Pei, Du, \& Zeng, 2016) and ethical behavior in family firms (Vallejo-Martos \& Puentes-Poyatos, 2014). Therefore there seems to be fertile ground in JMO for a research agenda studying the TMT/ family-owned firms/shared value approach as an alternative approach to governance.

What still seems to be lacking in JMO and more broadly in the academic community is an overarching theoretical perspective to integrate these diverse elements. Articles in JMO have used stakeholder theory and stewardship theory especially (e.g., Taniman \& O’Shannassy, 2015) to analyze how companies deal with a focus on shared value. These papers provide valuable insights and a step towards an integrated view on alternative governance models. However, they have not yet tied the external to the internal governance logic of the firm in the way agency and transaction cost theory does. Given the systemic nature of the connections we are looking for, it is surprising that the dominant strategy theory of the moment - the dynamic capabilities view - has been absent from this debate. The governance implications of nurturing and exploiting capabilities in the context of family firms and shared value remain unexplored. It seems that integrating insights from stakeholder and stewardship 
theory with the dynamic capabilities view could shed new light on the logic of alternative forms of governance. Before we continue to explore options for further research, the articles in this themed issue inform the debate about alternative governance by adding some new insights.

\section{THE ALTERNATIVE FORMS OF CORPORATE GOVERNANCE THEMED ISSUE}

Seven new articles are presented here in this themed issue. A governance-related theme running through the articles is the interaction of top managers and middle managers in the firm, allowing the firm to exhibit dynamic capabilities and deliver organization performance for shareholders and stakeholders. There are many different ways a firm can do this and our articles here give some insight into how this takes place.

First Jing (2018) in the small business setting of Australian retail pharmacies studies the effects of employee-perceived leadership paradigms comparing the performance outcomes of visionary leadership, organic or distributed leadership, classical leadership and transactional leadership. A sample 100 pharmacy stores in the Sydney suburbs provided 580 completed questionnaires from 100 managers, 217 staff members and 263 customers. Pharmacies were chosen for their highly educated workforce, which was expected to be more open to visionary and organic leadership styles. The structural equation modeling results find that visionary and organic leadership outperforms classical and transactional leadership in relation to financial performance, staff satisfaction and customer satisfaction. Manager tenure and staff tenure were both longer under the visionary leadership and organic leadership approaches. Long staff tenure also correlated positively with each of the performance measures.

There is a connection from the Jing (2018) findings to Teece (2018) and his explanation of the value to the firm of an understanding of the application of dynamic capabilities and also systems theory by executive leaders and managers. Teece (2018) points out the importance of learning and adaptation at the firm level, and the need for leaders and managers to have a holistic view of the firm to ensure all elements are in alignment - whether taking the dynamic capabilities or the systems theory approach to envisioning the future. He observes that the dynamic capabilities approach is different from systems theory in that firms led by leaders and managers not only can learn and adapt but they can often seek to shape the business environment. Dynamic capabilities allow systematic change for the firm in a rapidly changing business environment to start from within, with leaders and managers activating the firm sensing capability, integration capability and reconfiguration capability with the purpose of achieving competitive advantage. Dynamic capabilities are part of the system that is inclusive of resourcing and strategy choices that is the source of heterogeneity between firms and plays a role in determining whether competitive advantage is achieved or not. In this way Teece (2018) links systemslevel thinking with dynamic capabilities in his contribution here, but also highlights greater specificity of the dynamic capabilities framework on matters including the human element associated with the role of leaders and managers.

Next Javed, Rawwas, Khandhai, Shahid, and Tayyeb (2018) investigate the relationship between ethical leadership, trust in the leader, openness to experience and firm creativity using a survey questionnaire completed by both the work supervisor and subordinate in textile firms in Pakistan. The textile industry was chosen due to its focus on innovation practices. A total sample of 205 responses was obtained. The study found a positive association between ethical leadership and the dependent variable employee creativity; trust in the leader was found to mediate the relationship between ethical leadership and employee creativity. Openness to experience jointly with trust in the leader did not show a moderating relationship with the dependent variable. The study highlights the value of ethical leaders communicating well with employees to enhance employee commitment to the firm and their job, improving their creativity. 
Lee, Park, and Baker (2018) study the influence of top management support, human resource development efforts and job satisfaction on the dependent variable organizational commitment. This Korean study uses Korean Human Capital Corporate panel survey data with 3,899 responses from 159 large corporations; hierarchical multiple regression and regression-based path analyses are used for the hypothesis tests. The study finds that human resource development efforts are positively associated with the mediator variable job satisfaction and the dependent variable organizational commitment. Top management support is found to moderate the association between human resource development efforts and job satisfaction; job satisfaction mediates the moderation relationship of top management support jointly with human resource development efforts with the dependent variable organizational commitment.

Du, Zeng and Chang (2018) study the influence of internationalization on philanthropy and the moderating effect of the CEO's political participation using a sample of Chinese family firms for the period 2005-2011. Family firms in China are of interest as they are more likely to be internationalized than state-owned enterprises, contribute strongly to Chinese economic growth and have a stronger disposition to corporate philanthropy than state-owned enterprises. In this quantitative study the sample data collated from the China Stock Market and Accounting Research database includes 695 firms and 3,023 firm years. Using Tobit regression the study finds that there is a positive relationship between internationalization and corporate philanthropy in family firms. CEO political participation also reinforces the positive association between internationalization and corporate philanthropy. The emphasis on corporate philanthropy helps to overcome the liability of foreignness.

Kolodinsky, Ritchie, and Kuna (2018) studied the influence of a worker having a career 'calling' and perceived leadership support in a US-based email survey questionnaire that received 297 responses from millennial workers with an average age of 26 years old. Three survey scales were used to measure the research constructs career calling, perceived leadership support and work engagement respectively. The key finding of the multiple regression analysis was that the moderation term calling and leadership support jointly had a positive influence on the dependent variable work engagement.

We also wish to refer to insights from Zubac (2018) who writes that the field of strategic management has said little on the past, present and future of capitalism. Zubac (2018) explores the writings of three great economists - Joseph Schumpeter, Milton Friedman and Joseph Stiglitz - to identify where strategic management can make a robust contribution on the functioning of capitalism. Three areas where a contribution can be made are identified. First developing understanding of managerial strategic decision-making at different stages of the business cycle - especially how the firm can manage economic booms and busts. Second building understanding of markets - both free markets and mixed economies - in particular the influence of the achievement of temporary competitive advantage for a firm, and the influence of hypercompetition. Third scholars can look at how deeper insight into the three pillars of the modern theory of the firm (i.e., the theories of corporate finance, corporate governance and organizational design, respectively) can advance research into the firm itself, the development of new theories of the firm, and also help to build insight into the interaction of the firm and markets in a way that perpetuates market economies.

\section{Implications of the articles for an alternative governance approach}

The articles in this issue plus Zubac (2018) have been selected to inform the debate about alternative governance approaches we talk about and wish to stimulate research activity on here. Zubac (2018) provides the backdrop for these discussions, among others with the call for the development of new theories of the firm and relating that call to the inevitable booms and busts of capitalism. We identify three lessons from the articles in this issue that point to a direction of what an alternative theory may look like. First, Jing (2018), Lee, Park, and Baker (2018) and Kolodinsky, Ritchie, and Kuna (2018) 
look at the role of commitment or engagement; Javed et al. (2018) think along similar lines. This may be a central concept that may link TMTs with organic behavior, family-owned firms and shared value together. All of them may increase employee commitment and drive company results. The concept of commitment is noticeably absent from agency and transaction cost theory and could provide an element of a theory of alternative governance forms. Second, there is a variety of ways to achieve this commitment. Teece (2018) shows that to explain this heterogeneity the dynamic capabilities approach may be helpful. It could study the type dynamic capabilities that foster commitment, for example, and why levels and type of commitment differ between family firms. Third, the context is relevant and the integration of firms in their environment and the economy needs to be explained conceptually (Zubac, 2018). This also requires a further understanding of the context in which alternative governance models flourish. Du, Zeng, and Chang (2018) point to country of origin; Jing (2018) seems to imply the level of education may be relevant. This list is not complete, but obviously a theory about alternative governance models needs to explain the type of context in which the alternative governance mechanisms are effective.

\section{A FUTURE RESEARCH AGENDA}

We see a future research agenda in corporate governance as being much more than about the one-sided perspective of the application of agency or transaction cost theory to investigating the role of the CEO in public companies delivering shareholder value. The wider community and the business community is asking for much more with focus on the ethical delivery of shareholder and stakeholder value with sound practice of corporate social responsibility, however theoretical and empirical analysis on this has remained limited (O'Shannassy, 2015b). The one-sided perspective also constrains the development of insight into governance practices in small and medium-size enterprises and family firms, including the contribution that can be made by inside directors, top managers and middle managers who are motivated and responsible stewards of company resources (O'Shannassy, 2015b). So we can do more with our research agenda.

Specifically we now envision the next lines of research. First a review of existing literature may provide an overview of what we already know and what remains to be researched. With many publications dealing with parts of the problem, the need for a thorough overview of knowns and unknowns is high. Second conceptual work is necessary to further specify the mechanisms between the various elements of the alternative governance approach. Integration of stakeholder theory, stewardship theory and dynamic capabilities theory may be a fruitful approach; this should lead to an overarching logic that is as logical and elegant as the one provided by transaction cost economics and agency theory. Qualitative research may support these efforts especially in the context of family firms (Nordqvist, Hall, \& Melin, 2009). A relevant research question might be: What are the characteristics of dynamic capabilities that determine whether they lead to the creation of shared versus shareholder value? In addition it might be valuable to study how capability development differs for stock exchange listed versus family-owned firms. Are family firms better placed to nurture capabilities that deliver shared value? Bringing in notions from transaction cost and agency theory may further strengthen the framework. It may be especially valuable to look at the concept of opportunism that is central to traditional governance approaches and that may help to avoid an overly naïve view of governance (Foss \& Weber, 2016).

Third empirical research needs to address the connection between the three elements of TMTs/ family-owned firms/shared value. Interesting questions are how TMTs function in family-owned firms, whether family-owned firms focus more on shared value and whether companies which focus more on TMTs than individual CEO performance also focus more on shared value. Some of the papers in this themed issue begin to uncover these relationships and have shown the importance employee 
commitment plays. This calls for more research into commitment as a possible unifying concept behind the alternative governance approach.

Fourth, most studies have been performed within either stock exchange listed or family-owned firms. There is a lack of comparative studies into the real differences and similarities between them. Possible focus points here are differences in strategic choices they make, like the choice for mergers and acquisitions, restructuring and alliances (De Man, 2013).

Finally, we do not advocate one corporate governance model is better than the other. We merely advocate more attention should be paid to alternative models. It would be interesting to know more about the context in which the alternative governance perspective is more effective and when it is less effective. Research may point to the role of capital markets here. For example some firms may wish not to be listed to avoid having to make details about their strategies public. Cultural and technological circumstances may be of interest as well; national, regional and local culture can influence governance forms and the performance of dynamic capabilities in organizations in different ways in different legal jurisdictions (e.g., China mainland vs. Hong Kong region). For now here we have focused on TMTs, family-owned firms and shared value. There may be still other alternative governance models out there that require a similar research agenda (Davis, 2016).

\section{CONCLUSION}

JMO has devoted much attention to papers that provide building blocks for an alternative theory of corporate governance. We believe the Journal provides fertile ground for further development of that theory. It would require though that the considerable number of insights gained over the past few years are now transformed into a more coherent research agenda. This agenda should be directed towards creating an integrated model for alternative governance approaches that brings together the many small and diverse pieces of the puzzle that have been published over the past years.

\section{Timothy F O’Shannassy Graduate School of Business and Law, RMIT University, Melbourne, VIC, Australia}

Ard-Pieter de Man School of Business and Economics, Management \& Organization, Amsterdam Research Institute, Vrije Universiteit, Amsterdam, Netherlands and Graduate School of Business and Law, RMIT University, Melbourne, Australia

\section{References}

Basco, R., \& Voordeckers, W. (2015). The relationship between the board of directors and firm performance in private family firms: A test of the demographic versus behavioral approach. Journal of Management \& Organization, 21(4), 411-435.

Cabrera-Suárez, M., \& Martín-Santana, J. (2013). Top management teams and performance in non-listed family firms. Journal of Management \& Organization, 19(4), 405-423.

Davis, G. F. (2016). Can an economy survive without corporations? Technology and robust organizational alternatives. The Academy of Management Perspectives, 30(2), 129-140.

De Man, A. P. (2013). Alliances: An executive guide to designing successful strategic partnerships. Chichester: John Wiley \& Sons.

Du, X., Pei, H., Du, Y., \& Zeng, Q. (2016). Media coverage, family ownership, and corporate philanthropic giving: Evidence from China. Journal of Management \& Organization, 22(2), 224-253.

$\mathrm{Du}, \mathrm{X}$., Zeng, Q., \& Chang, Y. (2018). To be philanthropic when being international: Evidence from Chinese family firms. Journal of Management \& Organization, 24(3), 424-449. https://doi.org/10.1017/jmo.2017.9.

Foss, N. J., \& Weber, L. (2016). Moving opportunism to the back seat: Bounded rationality, costly conflict, and hierarchical forms. Academy of Management Review, 41(1), 61-79. 
Ghoshal, S., \& Moran, P. (1996). Bad for practice: A critique of the transaction cost theory. Academy of Management Review, 21(1), 13-47.

Grandori, A. (2016). Knowledge-intensive work and the (re) emergence of democratic governance. The Academy of Management Perspectives, 30(2), 167-181.

Javed, B., Rawwas, M. Y., Khandhai, S., Shahid, K., \& Tayyeb, H. H. (2018). Ethical leadership, trust in leader and creativity: The mediated mechanism and an interacting effect. Journal of Management \& Organization, 24(3), 388-405. https://doi.org/10.1017/jmo.2017.56.

Jensen, M. C., \& Meckling, W. H. (1976). Theory of the firm: Managerial behavior, agency costs and ownership structure. Journal of Financial Economics, 3(4), 305-360.

Jing, F. F. (2018). Leadership paradigms and performance in small service firms. Journal of Management \& Organization, 24(3), 339-358. https://doi.org/10.1017/jmo.2017.44.

Kiel, G., \& Nicholson, G. (2003). Board composition and corporate performance: How the Australian experience informs contrasting theories of corporate governance. Corporate Governance: An International Review, 11(3), 189-205.

Kolodinsky, R. W., Ritchie, W. J., \& Kuna, W. A. (2018). Meaningful engagement: Impacts of 'calling' work orientation and perceived leadership support. Journal of Management \& Organization, 24(3), 406-423. https://doi. org/10.1017/jmo.2017.19.

Lee, J. Y., Park, S., \& Baker, R. (2018). The moderating role of top management support on employees' attitudes in response to human resource development efforts. Journal of Management \& Organization, 24(3), 369-387. https:// doi.org/10.1017/jmo.2017.37.

Liu, Y., Valenti, A., \& Chen, Y. J. (2016). Corporate governance and information transparency in Taiwan's public firms: The moderating effect of family ownership. Journal of Management \& Organization, 22(5), 662-679.

Moran, P., \& Ghoshal, S. (1996). Theories of economic organization: The case for realism and balance. Academy of Management Review, 21(1), 58-72.

Nordqvist, M., Hall, A., \& Melin, L. (2009). Qualitative research on family businesses: The relevance and usefulness of the interpretive approach. Journal of Management \& Organization, 15(3), 294-308.

O'Shannassy, T. (2015a). Strategic management research in the Journal of Management \& Organization: International in orientation with an Australasian edge. Journal of Management \& Organization, 21(5), 551-557.

O'Shannassy, T. (2015b). The importance of the ethics of governance regime for the corporation and the connection to corporate governance practice. In M. Schwartz, H. Harris, \& D. Comer (Ed.), The Ethical Contribution of Organizations to Society (Research in Ethical Issues in Organizations, Vol. 14, pp. 41-55) England, UK: Emerald Group Publishing Limited.

Pichlak, M. (2016). The innovation adoption process: A multidimensional approach. Journal of Management \& Organization, 22(4), 476-494.

Porter, M. E., \& Kramer, M. R. (2011). The big idea: Creating shared value. How to reinvent capitalism—and unleash a wave of innovation and growth. Harvard Business Review, 89(1-2), 62-77.

Puranam, P., Alexy, O., \& Reitzig, M. (2014). What's "new" about new forms of organizing? Academy of Management Review, 39(2), 162-180.

Sanchez-Famoso, V., Maseda, A., \& Iturralde, T. (2017). Family involvement in top management team: Impact on relationships between internal social capital and innovation. Journal of Management \& Organization, 23(1), 136-162.

Taniman, C., \& O'Shannassy, T. (2015). Exploring the influence of chief executive officer professional development and work context on organisation performance: A multi-theoretic perspective. Journal of Management \& Organization, 21(5), 675-694.

Teece, D. J. (2018). Dynamic capabilities as (workable) management systems theory. Journal of Management \& Organization, 24(3), 359-368. https://doi.org/10.1017/jmo.2017.75.

Tian, Q., Liu, Y., \& Fan, J. (2015). The effects of external stakeholder pressure and ethical leadership on corporate social responsibility in China. Journal of Management \& Organization, 21(4), 388-410.

Vallejo-Martos, M., \& Puentes-Poyatos, R. (2014). Family firms as incubators for ethical behavior: An exploratory study from the perspective of stewardship theory. Journal of Management \& Organization, 20(6), 784-807.

Williamson, O. E. (1975). Markets and hierarchies. New York: Free Press.

Williamson, O. E. (1996). Economic organization: The case for candor. Academy of Management Review, 21(1), 48-57.

Zubac, A. (2018). Capitalism as discourse: How can strategic management scholars contribute new insights and refocus debate? Journal of Management \& Organization, 24(2), 189-208. https://doi.org/10.1017/jmo.2017.15. 